\title{
Active Thermal Control for Power Converters in Modular Winding Permanent Magnet Synchronous Motor
}

\author{
Hao Yan, Giampaolo Buticchi, Jiajun Yang, Weiduo Zhao, He Zhang, Chris Gerada \\ Faculty of Science and Engineering \\ University of Nottingham Ningbo China \\ Ningbo, China \\ yanhaohit@yahoo.com
}

\begin{abstract}
To increase the reliability and reduce the torque ripple, modular winding structure has been employed in the Permanent Magnet Synchronous Motors (PMSMs). However, the reliability of the motor system depends on the lifetime of the power semiconductor devices. In this paper, an Active Thermal Control (ATC) for modular power converters in PMSM drive is proposed. The power routing method is employed to balance the power in a triple modular winding PMSM system. The Rainflow Counting Algorithm is used to calculate the lifetime of the power converters. To verify the proposed method, a simulation model is established and the simulation results are presented.

Index Terms-Active thermal control, multi-phase motor, permanent magnet synchronous motor, modular inverter, motor control.
\end{abstract}

\section{INTRODUCTION}

In recent years, multi-phase Permanent Magnet Synchronous Motors (PMSMs) have played an important role in the highly reliable servo applications such as aerospace, electric vehicles and underwater equipments [1-3]. Among the multi-phase PMSMs, modular winding and multi-redundancy structure are significant techniques to increase the motor system reliability [4]. Meanwhile, with the development of power electronics, multi-level and multi-phase converters have been used in multi-phase PMSM drive system, which can improve the control performance and enhance the reliability [5].

In [6], a five-phase inverter is used to drive an induction motor. The performance of the five-phase modular winding motor is analyzed and this prototype can reduce the effect of space harmonics. More, to increase the capacity of the three-phase motor drive system, the three-level and five-level converter are researched [7]. The five-level inverter can help realizing the high voltage drive and reduce the output voltage THD. In [8], the multi-level converter can control a three-phase motor in a sensorless way. To reduce the torque ripple and increase the reliability, a dual three-level inverter topology is employed to drive an open-winding six-phase induction motor [9]. Besides, the model predictive direct flux vector control is used to control a multi-modular-winding induction motor [10].

In power converters, the reliability of power switches is the key factor that can determine the lifetime of motor drive system. Thus, it is of vital significance to improve the reliability of power switches. One major cause of failure in power devices and capacitors is caused by the thermomechanical fatigue in the connection point between different materials [11]. Fig. 1 shows the basic structure of a power device with different materials stacked on a direct-band-copper (DBC) substrate. Since the thermal expansion coefficients (CTE) of copper and ceramic of the substrate are different, the temperature variations, also called thermal cycles, can generate the mechanical stress between the material layers [12]. Then, the thermal cycles can lead to expansions and contractions of the materials, which causes aging. It is well known that the thermal cycle magnitude is a key parameter for the liftime of power semiconductor devices [13].

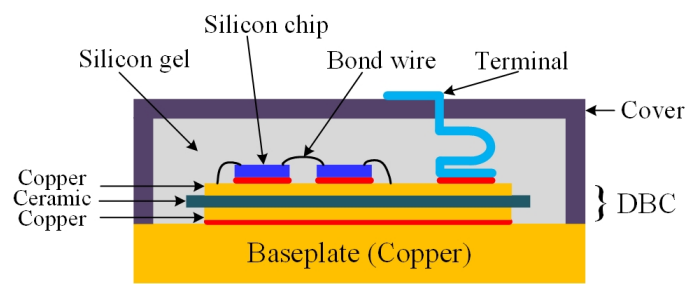

Fig. 1. Basic structure of a power semiconductor device [12].

Recently, Active Thermal Control (ATC) in power electronics has become an effective way to reduce the thermal cycling of power switches [14]. ATC is usually realized either by reducing the fluctuation amplitude or by reducing the mean level of the temperature, without modifications in the design of power converters [15-17]. Various ATC algorithms had been proposed in $[18,19]$ with the aim of reducing thermal stress in power modules.

Nevertheless, most of the ATC algorithms are focused on reducing the thermal cycling of one power converter or even one power device. Power routing is a technique that shifts the power between the cells of modular power converter to reduce the thermal stress of those cells, which exhibit a reduced residual lifetime [20]. Its application to modular drives with multiphase motors has not been reported in literature. Given the high reliability demand of the applications where modular 
winding PMSMs are used, increasing the reliability of power converters and extending their lifetime can further improve the motor system performance. For example, the power converters have different lifetime because the motor drive system is constantly repaired, then the lifetime of the whole motor system is determined by the lifetime of the weaker modular converter. However, with active thermal control based on power routing, the lifetime of different power converters can be equalized, which can further improve the system reliability.

To deal with the above problems, this paper proposes an ATC approach for power converters in modular winding PMSM drive. The Rainflow Couting Algorithm is used to estimate the accumulated damage of the power converters based on the measured temperature. Then the power routing method can control the lifetime of the system and reduce the power with high accumulated damage. The goal of the ATC is to extend the lifetime of the weaker power converter, and the total power is routed depending on the estimated lifetime.

The paper is organized as follows. Section II describes the lifetime estimation method of power converters. In Section III, the system and the proposed ATC method for modular power converters are introduced. A simulation validation is made in Section IV before the conclusions are presented in Section V.

\section{Lifetime Estimation OF POWER CONVERTERS}

\section{A. Basic Principles of Lifetime Estimation}

In the power converters, the failures of some components such as capacitors and power semiconductors can influence the lifetime. In this paper, only the failures in power semiconductors are taken into consideration. In actual situation, the power semiconductor manufacturers usually provide the time to failure by the number of thermal cycles to failure $N_{f}$. According to this, a well-known method, called CoffinManson-Arrhenius model [21], to estimate the lifetime of power semiconductors is expressed as following equation.

$$
N_{f}=k_{1} \cdot \Delta T^{-k_{2}} \cdot e^{\frac{k_{3}}{k_{B} T_{j, a v}}}
$$

where $\Delta T$ is the magnitude of the thermal cycles, $T_{j, a v}$ is the average junction temperature during the thermal cycle. $k_{1}, k_{2}$, $k_{3}$ are the fitting parameters extracted from multiple reliability experiments. $k_{B}$ is the Boltzmann constant.

In actual situation, the mission profile of an power converter is not deterministic, so a direct derivation of the accumulated damage with (1) is not suitable for estimate the lifetime. Therefore, a cycle counting method is required to decompose the temperature profile. In this case, the Rainflow Counting Algorithm is widely used cycle for fatigue analysis [22]. Then, the Miner's rule, expressed as (2), can be adopted to obtain the accumulated damage [23].

$$
D_{a}=\sum_{i} \frac{n_{i}}{N_{i}}
$$

Here, $D_{a}$ is the accumulated damage, $n_{i}$ the number of cycles in the stress range $i$, and $N_{i}$ the number of cycles to failure in the $i_{t h}$ stress range. Therefore, with the increase of the thermal cycles in the mission profile, the accumulated damage of power devices will rise. Once the value of $D_{a}$ reaches 1 , the power device will be in failure [11].

\section{B. Rainflow Counting Algorithm}

The lifetime of a power semiconductor device is depended on a variable mission profile, Rainflow Counting Algorithm is an effective approach to reduce the complex mission profile into some key events that can be used to estimate the lifetime. Fig. 2 illustrates the principles of Rainflow Counting Algorithm. To apply this method to power converters, the thermal expansion, stress and strain should be involved. In this application, the strain is the ratio of change in length of a material to its actual length based on the temperature change [24].
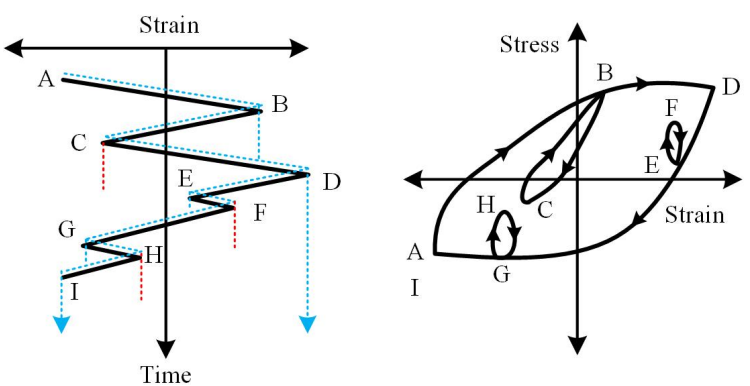

Fig. 2. Load sequence and stress-strain cycles in Rainflow Counting Algorithm.

Typically, the Rainflow Counting Algorithm is used to extract cycles from a load history, which can be obtained from temperature measurement. Based on the temperaturetime curve, the extrema and minima values are obtained, then the full, and half cycles are defined accordingly. Finally, the lifetime is estimated by using these cycles.

\section{Proposed Active Thermal Control for Modular Power Converters}

In this section, the proposed ATC method based on power routing in modular power converters is presented, and the implementation of the algorithm is explained.

\section{A. System Description of Modular Power Converters}

A triple modular PMSM drive system with three power converters is is chosen as an example to introduce the proposed ATC method. The motor drive system is shown in Fig. 3.

Each power converter is a two-level pulse width modulation voltage source inverter (PWM-VSI), and the three power converters share the same dc-link voltage $v_{d c}$. Given this parallel structure, the power of each converter can be expressed as (3). Here, $p_{\operatorname{con} 1}, p_{\operatorname{con} 2}$ and $p_{\text {con } 3}$ are the power of each inverter, and $i_{d c 1}, i_{d c 2}$ and $i_{d c 3}$ the dc-link current of each inverter.

$$
\left\{\begin{array}{l}
p_{c o n 1}=v_{d c} \cdot i_{d c 1} \\
p_{c o n 2}=v_{d c} \cdot i_{d c 2} \\
p_{c o n 3}=v_{d c} \cdot i_{d c 3}
\end{array}\right.
$$




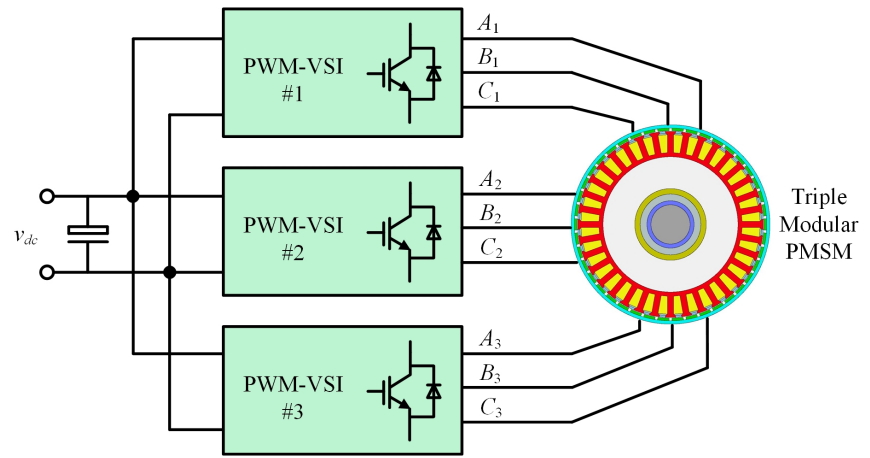

Fig. 3. Triple modular winding PMSM drive system.

More, the total power $p_{d c}$ equals to

$$
p_{d c}=p_{c o n 1}+p_{\text {con } 2}+p_{c o n} 3
$$

Fig. 4 demonstrates the equivalent circuit of one PWM-VSI. In this figure, $d_{a} \sim d_{c}, d_{a}{ }^{\prime} \sim d_{c}{ }^{\prime}$ are the duty cycles of the corresponding power switch, $v_{a}, v_{b}$ and $v_{c}$ are the three-phase terminal voltage.

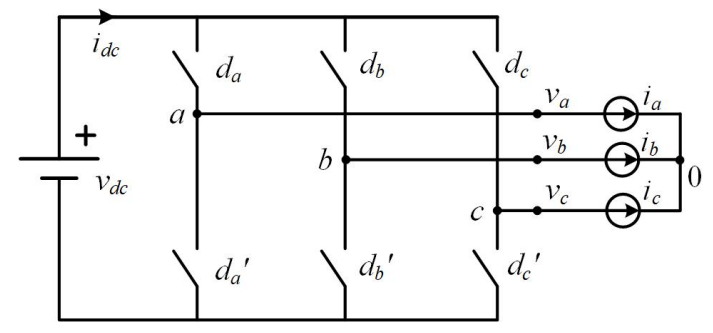

Fig. 4. Equivalent circuit of PWM-VSI.

The dc-link current can be calculated as

$$
i_{d c}=i_{a} d_{a}+i_{b} d_{b}+i_{c} d_{c}
$$

Assuming that the power converter losses are omitted, let $p_{d c}=p_{a c}$. By using the PARK coordinate transformation, the power of one PWM-VSI can be expressed as

$$
p_{d c}=v_{d c} \cdot i_{d c}=\frac{3}{2}\left(v_{d} i_{d}+v_{q} i_{q}\right)=p_{a c}
$$

Here, $v_{d}, v_{q}, i_{d}$ and $i_{q}$ are the voltage and current components under $d-q$ rotary coordinate system.

Combining (3), the power of the three power converters can be calculated as

$$
\left\{\begin{array}{l}
p_{\text {con } 1}=v_{d c} \cdot i_{d c 1}=\frac{3}{2}\left(v_{d 1} i_{d 1}+v_{q 1} i_{q 1}\right) \\
p_{c o n 2}=v_{d c} \cdot i_{d c 2}=\frac{3}{2}\left(v_{d 2} i_{d 2}+v_{q 2} i_{q 2}\right) \\
p_{c o n 3}=v_{d c} \cdot i_{d c 3}=\frac{3}{2}\left(v_{d 3} i_{d 3}+v_{q 3} i_{q 3}\right)
\end{array}\right.
$$

In this paper, the tested motor is a surface-mounted PMSM, so it should be controlled by the $i_{d}=0$ method to achieve the maximum torque. Therefore, (7) can be simplified as (8). It can be seen that the values of $q$-axis current in each winding will influence the power in each converter.

$$
\left\{\begin{array}{l}
p_{c o n 1}=v_{d c} \cdot i_{d c 1}=\frac{3}{2} v_{q 1} i_{q 1} \\
p_{c o n 2}=v_{d c} \cdot i_{d c 2}=\frac{3}{2} v_{q 2} i_{q 2} \\
p_{c o n 3}=v_{d c} \cdot i_{d c 3}=\frac{3}{2} v_{q 3} i_{q 3}
\end{array}\right.
$$

Normally, the motor operates in a random load condition, then the power of the power converters changes with time. Taking Fig. 5 as example, the red curve is the load mission profile of a motor. When the total power reaches $100 \%$, it means that all the three power converters are at full load, otherwise, some of the power converters are not at the rated load. The load mission profile determines the temperature as well as the lifetime of each converters, which can be used to verify the thermal control algorithms.

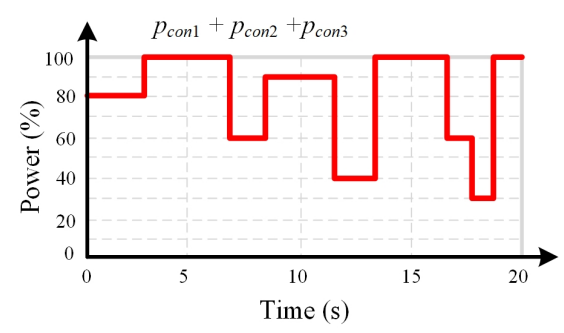

Fig. 5. Load mission profile.

\section{B. Thermal-based Power Routing Algorithm}

If the temperature of one certain converter is too high and the thermal cycles are increasing, the lifetime of the whole drive system will depend on the lifetime of the weakest converter. Then, too reduce the thermal stress of the weakest converter, the power in this converter need to be reduced and the power differences need to be distributed to the other two converters. By this way, the lifetime of motor drive system can be extended and the reliability increased [25].

Define $m_{d 1}, m_{d 2}$ and $m_{d 3}$ are the power distribution coefficients of the three converters, and calculated as

$$
\left\{\begin{array}{l}
m_{d 1}=\frac{p_{c o n 1}}{p_{d c}} \\
m_{d 2}=\frac{p_{c o n 2}}{p_{d c}} \\
m_{d 3}=\frac{p_{c o n 3}}{p_{d c}}
\end{array}\right.
$$

More, in (9), $m_{d 1}+m_{d 2}+m_{d 3}=1$. In a normal operation, the power distribution coefficients are equally distributed as

$$
m_{d 1}=m_{d 2}=m_{d 3}=\frac{1}{3}
$$

However, in ATC operation, the power distribution coefficients are distributed by the converter temperature. In Fig. 6, the block diagram of the proposed ATC method is illustrated.

According to (8), the power in each converter can be routed with the control of $q$-axis current loop. The total power reference $p_{d c}^{*}$ is determined by the load mission profile, ranged from 0 to 1 . Temperature sensors are placed on each power converter and sample the device junction temperature. The temperature references are given by software and compared 


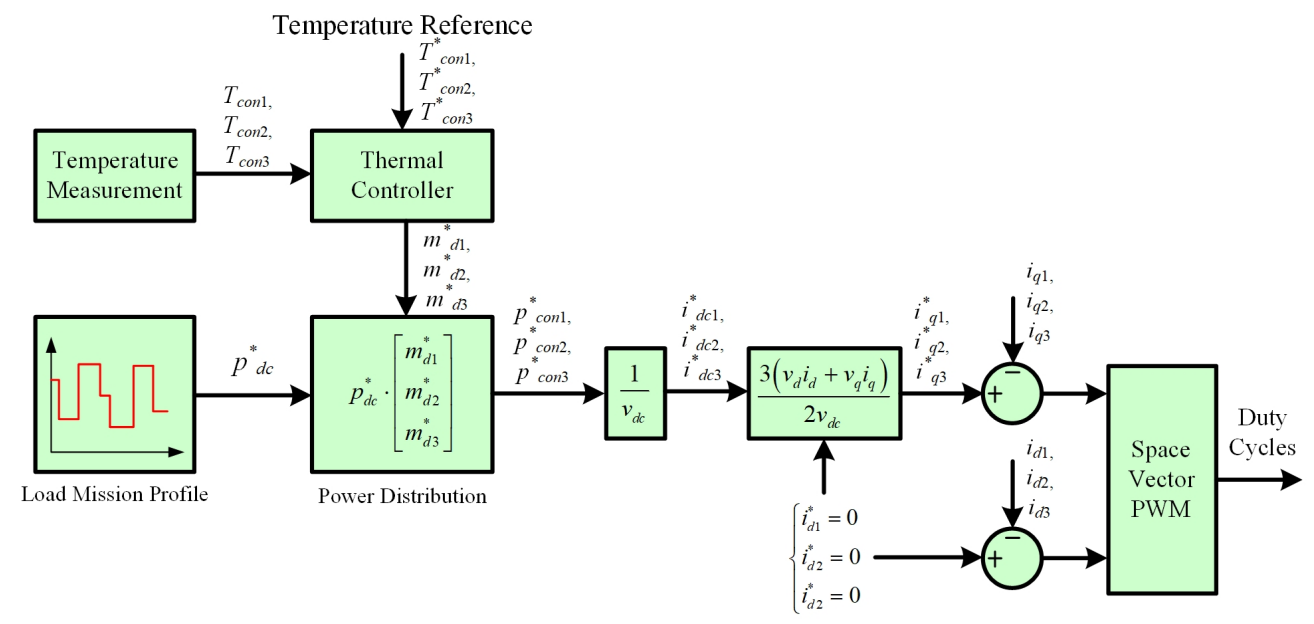

Fig. 6. Block diagram of the proposed ATC.

with the measured temperature, then the thermal controller calculates three power distribution coefficients $m_{d 1}^{*}, m_{d 2}^{*}$ and $m_{d 3}^{*}$, which are used to obtain the power references of the three converters $p_{\text {con } 1}^{*}, p_{\text {con } 2}^{*}$ and $p_{\text {con } 3}^{*}$. Based on the Field Oriented Control (FOC) for PMSM, the $d$-axis and $q$-axis current references of three current loops are obtained and then the Space Vector PWM signals are generated to drive the motor.

Fig. 6 mainly explains the principles of ATC. To clearly illustrate the implementation of the triple modular winding PMSM control algorithm, the block diagram of the speed and current double-close-loop motor control algorithm is presented in Fig. 7. In the speed controller, the motor speed reference and measured motor speed are compared and calculated with a Proportional-Integral (PI) controller. The $d$-axis and $q$-axis current references are calculated with ATC algorithm. Since the motor is a surface-mounted PMSM, the three $d$-axis current references $i_{d 1}^{*}, i_{d 2}^{*}$ and $i_{d 3}^{*}$ should be set as zero. Six PI controllers are used to control the current loop and three reference voltage vectors are generated after the current loop. Then, with Space Vector PWM (SVPWM), the PWM signals to drive the inverters are obtained. Finally, the modular winding PMSM is driven by the three PWM-VSIs.

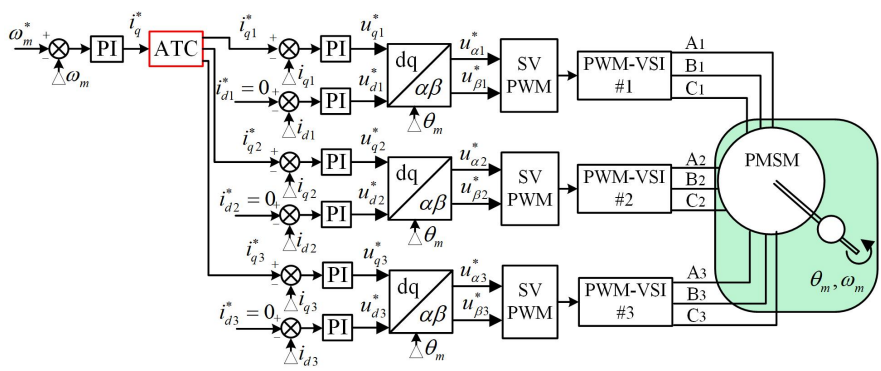

Fig. 7. Block diagram of the speed and current double-close-loop control for the triple modular winding PMSM.

\section{Simulation Verification}

\section{A. Simulation Model Setup}

To verify the proposed ATC method, the PLECS simulation model is established and simulated. The modular winding PMSM with a 36-slot-42-pole structure, and the control parameters are reported in Table I.

TABLE I

Simulation Model Parameters

\begin{tabular}{cc}
\hline \hline Parameters & Quantity \\
\hline Winding resistance $\left(R_{a}\right)$ & $2.875 \Omega$ \\
Winding inductance $\left(L_{a}\right)$ & $8.5 \mathrm{mH}$ \\
Flux linkage $\left(\varphi_{m}\right)$ & $0.175 \mathrm{Vs}$ \\
Moment of inertia $(J)$ & $0.00082 \mathrm{~N} \cdot \mathrm{ms}^{2}$ \\
Number of pole pairs $(p)$ & 4 \\
DC-link voltage $\left(V_{d c}\right)$ & $300 \mathrm{~V}$ \\
Rated torque $\left(T_{N}\right)$ & $50 \mathrm{~N} \cdot \mathrm{m}$ \\
Rated speed $\left(n_{N}\right)$ & $1500 \mathrm{r} / \mathrm{min}$ \\
PWM frequency $\left(f_{p w m}\right)$ & $20 \mathrm{kHz}$ \\
\hline \hline
\end{tabular}

In the simulation, the thermal circuit model is used to calculate the temperature of each power converter. Fig. 8 shows the thermal model of the power converter. The power losses are calculated with the conduction and switching losses of the power switches. $T_{a m}$ is the ambient temperature which is set as $50^{\circ} \mathrm{C}$. The thermal chain contains two thermal capacitors and two thermal resistors, whose values are set as follows: $R_{t h 1}=0.018 \mathrm{~K} / \mathrm{W}, R_{t h 2}=0.172 \mathrm{~K} / \mathrm{W}, C_{t h 1}=0.95$ $\mathrm{J} / \mathrm{K}, C_{t h 2}=0.24 \mathrm{~J} / \mathrm{K}$. To verify the proposed ATC, the thermal chain in PWM-VSI\#3 is increased, which can cause the temperature differences between different converters. In the actual operating situation, the temperature between the power converters is not uniform because of the different heat dissipation conditions.

\section{B. Simulation Results}

Fig. 9 shows the junction temperature of the power switches of the three power converters before and after the proposed 


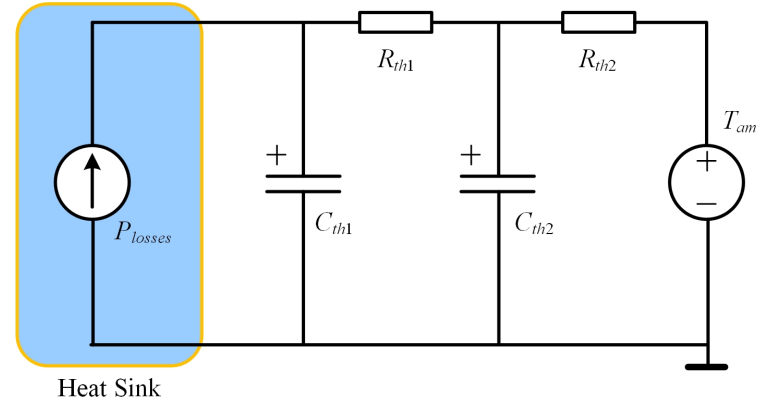

Fig. 8. Thermal model of the power converter.

ATC. In the simulation, the load mission profile changes every two seconds, which cause the temperature fluctuations in the two figures. It is obvious that the junction temperature $T_{j}$ in the PWM-VSI\#3 is reduced with ATC. For example, at the instant $t=14 \mathrm{~s}, T_{j}$ in the PWM-VSI\#3 reduces from $70.93^{\circ} \mathrm{C}$ to $69.19^{\circ} \mathrm{C}$ with ATC.

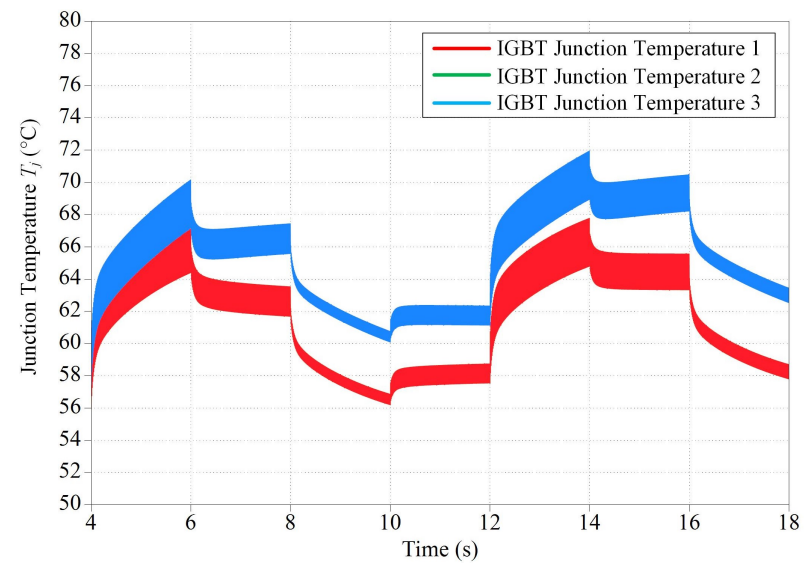

(a)

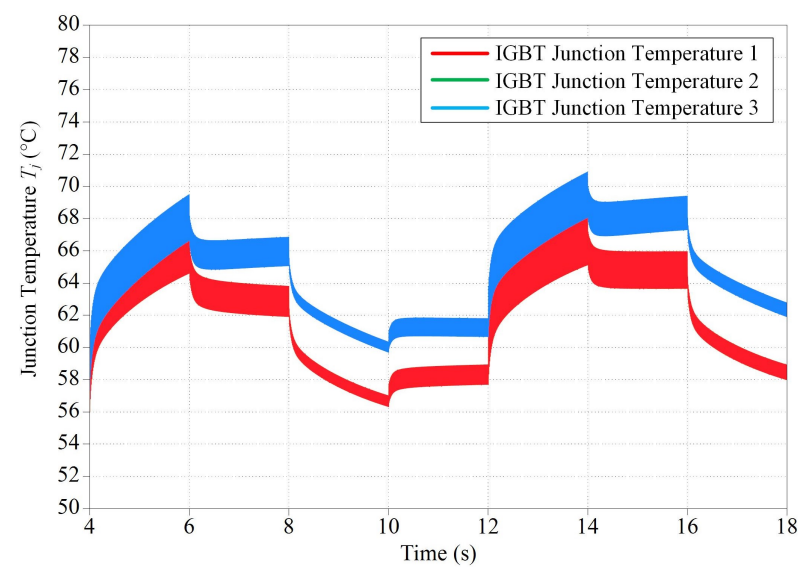

(b)

Fig. 9. Simulation results of IGBT junction temperature in each power converter. (a) Without ATC. (b) With ATC.

Fig. 10 shows the power distribution coefficients of the three converters with ATC. It can be seen that the power distribution coefficient $m_{d 3}$ decreases because of the high junction temperature in PWM-VSI\#3.

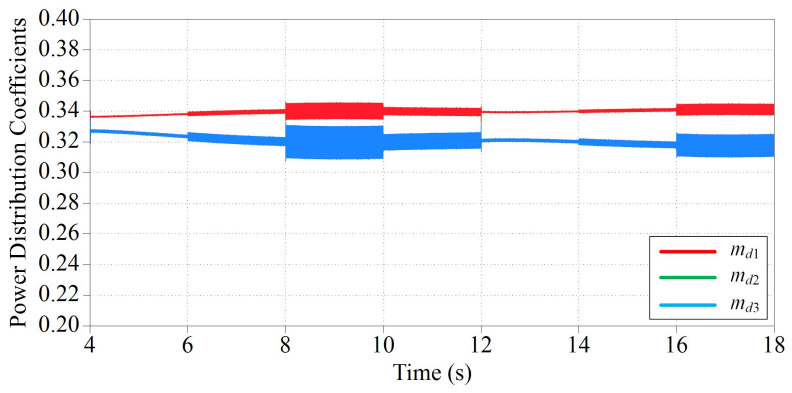

Fig. 10. Power distribution coefficients of each converter under ATC.

To calculate the lifetime, Rainflow Counting Algorithm is employed. Fig. 11 shows the calculated thermal cycles with Rainflow Counting Algorithm. In the simulation, the lifetime of the power switch increases $10.44 \%$ with the proposed ATC, which validates the effectiveness of the proposed method.

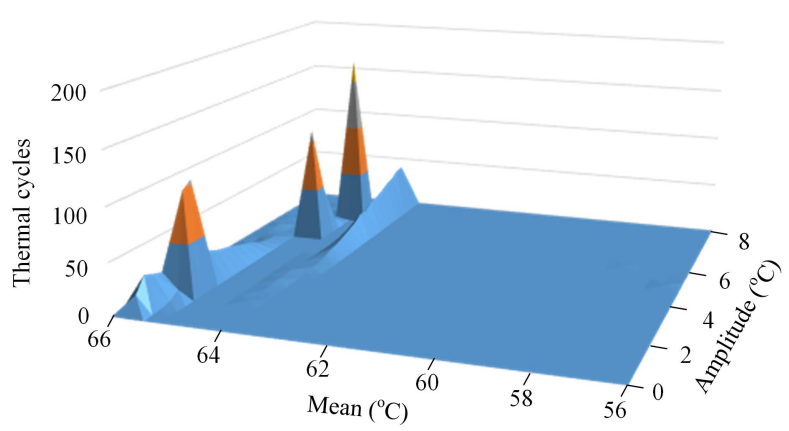

Fig. 11. Temperature cycle measurement with Rainflow Counting Algorithm and the proposed ATC.

\section{CONCLUSions}

To increase the reliability in the modular winding PMSM drive system, an ATC method based on power routing is proposed. From the simulation results, the junction temperature of the power switches reduces with ATC. More, the power distribution coefficient of the weaker converter is decreased, which can reduce the thermal cycles. Besides, to calculate the lifetime, the Rainflow Counting Algorithm is employed. The lifetime of the weaker power converter is increased $10.44 \%$ with the porposed ATC. The proposed method is an effective approach to increase the lifetime and reliability of the power converters in the modular winding PMSM drive system.

\section{ACKNOWLEDGMENT}

This work was supported in part by the National Natural Science Foundation of China under Grant 51807099 and Grant 51807100 , and in part by the Ningbo Science and Technology Beauro under Grant 2014A35007. 


\section{REFERENCES}

[1] M. Villani, M. Tursini, G. Fabri, and L. Castellini, "High reliability permanent magnet brushless motor drive for aircraft application," IEEE Trans. Ind. Electron., vol. 59, no. 5, pp. 2073-2081, May 2012.

[2] Y. Demir and M. Aydin, "A novel dual three-phase permanent magnet synchronous motor with asymmetric stator winding," IEEE Trans. Magn., vol. 52, no. 7, pp. 1-5, Jul. 2016.

[3] M. Onsal, Y. Demir, and M. Aydin, "A new nine-phase permanent magnet synchronous motor with consequent pole rotor for high-power traction applications," IEEE Trans. Magn., vol. 53, no. 11, pp. 1-6, Nov. 2017.

[4] A. S. Abdel-Khalik and S. Ahmed, "Performance evaluation of a five-phase modular winding induction machine," IEEE Trans. Ind. Electron., vol. 59, no. 6, pp. 2654-2669, Jun. 2012.

[5] Z. Pan and R. A. Bkayrat, "Modular motor/converter system topology with redundancy for high-speed, highpower motor applications," IEEE Trans. Power Electron., vol. 25, no. 2, pp. 408-416, Feb. 2010.

[6] A. S. Abdel-Khalik and S. Ahmed, "Performance evaluation of a five-phase modular winding induction machine," IEEE Trans. Ind. Electron., vol. 59, no. 6, pp. 2654-2669, Jun. 2012.

[7] H. Hosoda and S. Peak, "Multi-level converters for large capacity motor drive," in Proc. Int. Power Electronics Conf. - ECCE ASIA -, Jun. 2010, pp. 516-522.

[8] S. Kamel, S. Mark, and A. Greg, "Sensorless control of induction motors using multi-level converters," IET Power Electron, vol. 5, no. 2, pp. 269-279, Feb. 2012.

[9] K. K. Nallamekala and K. Sivakumar, "A fault-tolerant dual three-level inverter configuration for multipole induction motor drive with reduced torque ripple," IEEE Trans. Ind. Electron., vol. 63, no. 3, pp. 1450-1457, Mar. 2016.

[10] S. Rubino, R. Bojoi, S. A. Odhano, and P. Zanchetta, "Model predictive direct flux vector control of multithree-phase induction motor drives," IEEE Trans. Ind. Appl., vol. 54, no. 5, pp. 4394-4404, Sep. 2018.

[11] M. Andresen, K. Ma, G. Buticchi, J. Falck, F. Blaabjerg, and M. Liserre, "Junction temperature control for more reliable power electronics," IEEE Trans. Power Electron., vol. 33, no. 1, pp. 765-776, Jan. 2018.

[12] B. Ji, V. Pickert, W. Cao, and B. Zahawi, "In situ diagnostics and prognostics of wire bonding faults in IGBT modules for electric vehicle drives," IEEE Trans. Power Electron., vol. 28, no. 12, pp. 5568-5577, Dec. 2013.

[13] M. Andresen, V. Raveendran, G. Buticchi, and M. Liserre, "Lifetime-based power routing in parallel converters for smart transformer application," IEEE Trans. Ind. Electron., vol. 65, no. 2, pp. 1675-1684, Feb. 2018.

[14] P. K. Prasobhu, V. Raveendran, G. Buticchi, and M. Liserre, "Active thermal control of GaN-based DC/DC con- verter," IEEE Trans. Ind. Appl., vol. 54, no. 4, pp. 35293540, Jul. 2018.

[15] V. Blasko, R. Lukaszewski, and R. Sladky, "On line thermal model and thermal management strategy of a three phase voltage source inverter," in Proc. Conf. Record of the 1999 IEEE Industry Applications Conf.. Thirty-Forth IAS Annual Meeting (Cat. No.99CH36370), vol. 2, Oct. 1999, pp. 1423-1431 vol.2.

[16] M. Weckert and J. Roth-Stielow, "Lifetime as a control variable in power electronic systems," in Proc. Emobility - Electrical Power Train, Nov. 2010, pp. 1-6.

[17] M. Andresen, K. Ma, G. Buticchi, J. Falck, F. Blaabjerg, and M. Liserre, "Junction temperature control for more reliable power electronics," IEEE Trans. Power Electron., vol. 33, no. 1, pp. 765-776, Jan. 2018.

[18] D. A. Murdock, J. E. R. Torres, J. J. Connors, and R. D. Lorenz, "Active thermal control of power electronic modules," IEEE Trans. Ind. Appl., vol. 42, no. 2, pp. 552 558, Mar. 2006.

[19] M. Andresen, G. Buticchi, and M. Liserre, "Study of reliability-efficiency tradeoff of active thermal control for power electronic systems," Microelectronics Reliability, vol. 58, pp. 119-125, 2016.

[20] M. Liserre, M. Andresen, L. Costa, and G. Buticchi, "Power routing in modular smart transformers: Active thermal control through uneven loading of cells," IEEE Trans. Ind. Electron. Mag., vol. 10, no. 3, pp. 43-53, Sep. 2016.

[21] M. Held, P. Jacob, G. Nicoletti, P. Scacco, and M.-. Poech, "Fast power cycling test of IGBT modules in traction application," in Proc. Second Int. Conf. Power Electronics and Drive Systems, vol. 1, May 1997, pp. 425-430 vol.1.

[22] M.Matsuishi and T. Endo, "Fatigue of metals subjected to varying stress," Proc. Jpn. Soc. Mech. Eng., pp. 37-40, Mar. 1968.

[23] M. Musallam and C. M. Johnson, "An efficient implementation of the rainflow counting algorithm for life consumption estimation," IEEE Trans. Rel., vol. 61, no. 4, pp. 978-986, Dec. 2012.

[24] L. R. GopiReddy, L. M. Tolbert, B. Ozpineci, and J. O. P. Pinto, "Rainflow algorithm-based lifetime estimation of power semiconductors in utility applications," IEEE Trans. Ind. Appl., vol. 51, pp. 3368-3375, 2015.

[25] A. Marquez, J. I. Leon, S. Vazquez, and L. G. Franquelo, "Closed-loop active thermal control via power routing of parallel DC-DC converters," in Proc. IEEE 12th Int. Conf. Compatibility Power Electronics and Power Engineering (CPE-POWERENG 2018), Apr. 2018, pp. 1-6. 